\title{
¿SE DEBE LA POSPOSICIÓN DEL SUJETO EN EL ESPAÑOL A UNA INFLUENCIA ÁRABE?
}

\author{
Reinhard Meyer-Hermann \\ Universidad de Bielefeld
}

\section{INTRODUCCIÓN}

$\mathrm{El}$ orden de los constituyentes sujeto (S), verbo (V) y objeto (O) en la oración española ha sido tema en los últimos años de numerosas investigaciones. Estas son, por una parte, motivadas por el interés en la tipología lingüística cuando se trata de averiguar el orden "normal" en español de estos constituyentes (véase Ruhlen, 1975; Givón, 1983; Hawkins, 1983). Por otra parte, hay investigaciones dedicadas al problema de la función comunicativa o interactiva que se realiza en ciertos órdenes entre sujeto, verbo y objeto especialmente, en la lengua hablada. En este marco la investigación se ha dirigido preferentemente hacia los procedimientos y la función de la topicalización, es decir, al estudio de los diferentes modos de convertir un elemento de la oración en tópico (véase Ariza, 1978, con amplia bibliografía ; Rivero, 1980 ; Morales de Walters, 1982 ; Silva-Corvalán, 1982 y 1984 ; Bentivoglio, 1983; Fant, 1984; Torrego, 1984 ; Meyer-Hermann, 1987a y 1987b) ${ }^{1}$.

El estudio de los problemas mencionados tiene al lado de su dimensión sincrónica una dimensión diacrónica. Parte de la "explicación" de las estructuras del español actual consiste en comparar éstas con estructuras más antiguas del mismo, e indicar causas de los cambios sufridos por el idioma.

1 El presente estudio trata sólo de un aspecto contenido en un proyecto de investigación, en el cual presento un análisis descriptivo de las formas y funciones de la topicalización en las lenguas románicas bajo la perspectiva sincrónica y diacrónica (véase, respecto a ello, Meyer-Hermann, 1987 b). Una versión sucinta de este trabajo será publicada en las Actas del I Congreso Internacional de Historia de la Lengua Española (Cáceres, 1987), Madrid, Arco/Libros, 1988, I, págs. 541-562. 
Al tratar de "explicar" un "desarrollo" lingüístico, o mejor dicho, diferencias entre dos o más estados del idioma en cuestión en dos o más momentos diferentes $t_{1}, t_{2}, \ldots t_{n}$, se recurre con frecuencia al factor llamado "influencia" 2. Suponer tal "influencia" por parte del árabe en el desarrollo del latín tardío pasando por el romance al castellano es un topos en el estudio de la historia de la lengua española.

\section{El Árabe y el orden de sujeto, Verbo, objeto en español}

\subsection{Orientación}

La amplia herencia del árabe en el léxico del español no necesita más presentación (véase el diccionario que a pesar de su antigüedad no ha dejado de ser el más amplio en la materia, Dozy/Engelmann, 1869, y amplia bibliografía en Lapesa, 1981, págs. 133-140). Contrasta con eso, de forma llamativa, la poca atención que todos los trabajos especializados en la materia recogen sobre la influencia del árabe en la sintaxis española. Lo más esencial que encontramos en la obra de Baldinger sobre la "Formación de los dominios lingüísticos en la Península Ibérica" (véase Baldinger, 1972), publicada por primera vez en el año 1958, la cual, aún, sigue siendo una obra fundamental, es solamente una referencia a un pequeño estudio del romanista de Erlangen $H$. Kuen (1958). También Lapesa (1981) se limita, en cuanto a este punto, a remitirse a Kuen, sin profundizar más (véanse páginas 151/152). El párrafo esencial en el trabajo de Kuen dice:

No debe ser una casualidad el hecho de que precisamente en español y en portugués ocupe el verbo una posición inicial en la frase con mayor frecuencia que en ningún otro idioma románico, puesto que lo normal en árabe es que el verbo comience la frase (citado según Baldinger, 1958, pág. 85, nota 70$)^{3}$.

Kuen no da ninguna prueba que confirme su afirmación, y tampoco nos permiten llegar a conclusiones que pudiesen sostener la tesis de él, otras investigaciones sobre el tema (véase, por ejemplo, Crabb, 1955 y Galmés

2 Pongo entre comillas los términos "explicación", "desarrollo", "influencia”, etc., para distanciarme de su empleo, que en muchas ocasiones es metodológicamente ingenuo. Pero tengo que abstenerme de desarrollar, en el marco de este artículo, el necesario debate que debería de haber sobre estos conceptos.

\& En el original alemán aparece: “(...) es dürfte kein Zufall sein, daß gerade im Spanischen und Portugiesischen das Verbum häufiger als in irgendeiner anderen romanischen Sprache den Satz eröffnet, denn im Arabischen ist die Voranstellung des Verbums die Regel” (Kuen, 1958, pág. 16). 
de Fuentes, 1955/56), en parte, porque son insuficientes los datos en los que se fundamentan, $y$, en parte, por falta de una metodología adecuada . Por eso tiene razón Lapesa de exigir:

La hipótesis necesitaría comprobarse con un estudio riguroso del orden de palabras español en sus distintas épocas y niveles, parangonado con el de las demás lenguas románicas, el árabe y el hebreo (Lapesa, 1981, página 152).

El presente estudio es el primero de una serie de investigaciones, en las cuales me he propuesto esclarecer, entre otros problemas, la cuestión de si el español reune caracteristicas de una lengua con la estructura VSO y si, en este caso, pudiera ser empíricamente comprobada una influencia árabe (Tomlin, 1986, pág. 238, no conociendo todavía a Givón, 1983, califica el español, conforme a los trabajos de Ruhlen, 1975 y Hawkins, 1983, como lengua SVO).

\subsection{Posposición del sujeto y topicalización en español}

Para los fines de este artículo podemos basarnos en la fórmula simplificada de que el tópico de una frase es aquel constituyente que representa el tema de ella. Supongo, ad hoc, que la oración afirmativa normal en español está caracterizada por el orden SVO. Supongo, además, que el sujeto representa el tópico, o sea, el tema, y que el verbo con el objeto suministra “información” (rema) sobre el tópico. He aquí un ejemplo como ilustración:

(1) Fermando I inició la actividad militar y ocupó, entre los años 1055 y 1064, importantes plazas estratégicas en el oeste (Viseo, Lamego y, especialmente, Coimbra). Pero su hijo Alfonso VI dio el paso decisivo con la espectacular ocupación de Toledo (1085).

Conforme a la definición que establece la topicalización como procedimiento lingüístico por el cual un constituyente se convierte en tópico, el hecho de colocar el objeto sintáctico a la izquierda del verbo representa un procedimiento de topicalización, como lo muestra el ejemplo (2):

- El método que, por ejemplo, utiliza Crabb en su estudio es problemático al menos en dos aspectos. Compara una traducción española de la Biblia, para la cual sirvió de modelo un texto hebreo o árabe, con una traducción francesa basada en la Vulgata. La traducción del árabe al español es siempre problemática, por un lado porque hay interferencias inherentes propias de cualquier traducción que la apartan de las estructuras del español no traducido, por otro lado hay que atribuir parte de las diferencias que se dan en las traducciones a las diferentes versiones de la Biblia que a las mismas sirvieron de modelo. 
(2) La actividad militar la inició Fernando I, el cual ocupó, entre los años 1055 y 1064, importantes plazas estratégicas en el oeste (Viseo, Lamego y, especialmente, Coimbra). Pero el paso decisivo lo dio su hijo Alfonso VI con la espectacular ocupación de Toledo (1085). (Historia de España, IV, pág. 16).

A través de este "desplazamiento a la izquierda" del objeto directo se mueve el sujeto (aunque no necesariamente) a la derecha del verbo, convirtiéndose la actividad militar y el paso decisivo en el tópico y, a la vez, en el tema de las dos frases del ejemplo (2).

Es evidente que este desplazamiento a la izquierda del objeto directo solamente puede funcionar como topicalización si el orden, como tal, de los constituyentes tiene una función comunicativa, independiente de su función sintáctica. Dicho de otro modo: desplazamiento a la izquierda del objeto directo como procedimiento de topicalización supone el orden SVO como orden "normal" de los constituyentes en español. (Véase Meyer-Hermann 1988).

La afirmación de Kuen de que en español, en comparación con otras lenguas románicas, se coloque el verbo con mayor frecuencia en la posición inicial de la frase, necesita algunas precisiones. ¿Quiere eso decir que el sujeto está pospuesto en, por ejemplo, el 60 por ciento de los casos? ¿Cuál es, entonces, el orden "normal" entre los constituyentes S, V y O en español? ¿Cuántos de estos 60 por ciento de sujetos pospuestos corresponden al orden VSO, y cuántos al orden OVS causado por la topicalización (desplazamiento a la izquierda)? La respuesta a todas estas preguntas tiene su relevancia propia, y esto independientemente de la comparación del español con otras lenguas románicas, en las que, al parecer, no se pospone el sujeto con tanta frecuencia, y también independientemente de una eventual influencia árabe en el orden de los constituyentes en español. En el caso de que el sujeto estuviese, en términos absolutos, colocado con mayor frecuencia detrás, y no delante, del verbo, debería de ser considerada, a la hora de establecer estadísticamente el concepto del orden normal, la posición a la derecha del verbo como posición "normal" del tópico. Ya no sería, entonces, el desplazamiento a la izquierda del objeto directo un procedimiento de topicalización, no siendo que se desechase la equiparación del sujeto con el tópico (en la oración afirmativa normal). Es evidente que a través de una cuidadosa interpretación de datos estadísticos se podría contestar un gran número de las preguntas mencionadas. 


\subsection{Metas de investigación}

Después de estos preliminares se pueden precisar las metas del presente estudio de la manera siguiente:

a) Determinar la frecuencia de la posposición del sujeto en el español del siglo xıI y en el español actual.

b) Determinar la frecuencia de la posposición del sujeto en un idioma no iberorrománico, como, por ejemplo, el francés del siglo xiII y el francés moderno.

c) Investigar la posible influencia del árabe en la posición del sujeto con respecto al español antiguo, y así, indirectamente, en el español moderno.

d) Explicar identidades y/o diferencias del español con el francés en cuanto a la posición del sujeto en estos idiomas.

\section{Metodología de ESTE estudio}

\subsection{Los textos}

\subsubsection{Consideraciones previas}

La selección de los textos que voy a utilizar la he llevado a cabo de acuerdo con las metas indicadas en la parte 2.3. y, más en concreto, en los puntos a) y c) de la misma. Deben de ser textos escritos en castellano antiguo o leonés antiguo, entre los cuales hay que comparar textos que hayan sido redactados (o lo pudieran ser) bajo "influencia" árabe con otros exentos de tal "influencia". Además, deben de ser lo suficientemente extensos para permitir conclusiones generalizadas. Como textos que reunen éstas, y otras, condiciones favorables para investigaciones lingüísticas en general, y que, además, responden a los fines de nuestro estudio en particular, se nos presentan los fueros. Entre los textos primitivos no literarios de la Edad Media son, precisamente, los fueros los textos más extensos, los cuales, y a diferencia, por ejemplo, de las actas notariales, apenas estaban sujetos a las normas estilísticas de la cancillería (véase Gimeno Menéndez 1985/86, páginas 346-347). Se sabe que los autores de los mismos eran, en la mayoría de los casos, jurisconsultos, pero por las innumerables inconsistencias internas que presentan, además de otros indicios, se puede 
inferir que no los redactaron teniendo en cuenta rigidas normas estilisticas. Por otra parte, y como consecuencia de haber sido redactados muchos de los fueros siguiendo, mutatis mutandis, el modelo de los ya existentes, presentan la mayoria de ellos estructuras semejantes o idénticas, que nos permiten llegar a un alto grado de comparabilidad. Esa comparabilidad se extiende más allá de los límites de la Península Ibérica. Así, los coutumiers en Francia equivalen a los fueros de la Península Ibérica. Este término francés indica la consolidación del derecho consuetudinario en textos legislativos, lo que también es aplicable a los fueros. (Véase Gilissen 1982).

\subsubsection{Los textos españoles}

Como textos ejemplares para el análisis del español antiguo me he servido, por una parte, de los Fueros de Salamanca y Zamora y, por otra parte, del de Sepúlveda. La selección de los Fueros de Salamanca y Zamora se basa en la hipótesis de una posible influencia árabe en la estructura de los nismos, debida a una probable participación de mozárabes en su redacción. La hipótesis contraria se sostiene con respecto al Fuero de Sepúlveda, argumentando que fue escrito solamente por castellanos y quedando, por consiguiente, exento de la influencia de hispanorromanos conocedores del árabe.

Si se considera válida la hipótesis que sostiene la "influencia árabe" en el origen de los Fueros de Salamanca y Zamora -en su apoyo presentaré algunos argumentos en la parte siguiente- y si compartimos la hipótesis que defiende que una influencia árabe en la sintaxis del español antiguo ha originado, entre otras cosas, la frecuente posposición del sujeto, se puede, entonces, suponer que en los fueros "influenciados por el árabe" de Salamanca y Zamora se dé con mayor frecuencia la posposición del sujeto que en el caso del Fuero de Sepúlveda, que queda libre de tal "influencia".

Al aplicar el método de la comparación a los fueros, emprendo un camino distinto al seguido tradicionalmente en la investigación de arabismos, que, por regla general, se basa en el análisis de traducciones del árabe al castellano ${ }^{5}$, desempeñando en ello un papel importante los textos elaborados en el siglo XII por la llamada escuela de traductores de Toledo ${ }^{6}$. Este método de analizar traducciones en castellano, procedentes de textos ára-

s Método también empleado por Galmés de Fuentes (1955/56) en su extenso estudio, que, no obstante su metodología problemática, es muy instructivo.

- Véase G. Menéndez Pidal (1951). Valdeón Baruque (1980, pág. 85) afirma, sin embargo: "En realidad, la citada escuela parece que nunca existió. Lo que sí se produjo fue un encuentro de intelectuales de diversas latitudes que acudían a Toledo, atraídos por su fama, con la finalidad de entrar en contacto con las obras árabes y verterlas al latín". 
bes, con el fin de averiguar los posibles arabismos introducidos, me parece claramente erróneo, porque en las traducciones se producen, con cierta regularidad, interferencias con el idioma de origen, que bien pueden haberse introducido de forma impremeditada como premeditadamente para imitar, por los motivos más diversos que ni siquiera se conocen, la lengua o el estilo del original. Dicho de otro modo: el hecho de que encontremos un arabismo en un texto traducido del árabe al castellano antiguo o al leonés antiguo, no prueba la penetración de este arabismo en el uso general y popular de la lengua. De la misma manera que el empleo de un galicismo en una traducción al español de un texto de Sartre no significa que este galicismo forme parte del uso de la lengua española.

De acuerdo con lo expuesto, defiendo la opinión de que los arabismos, que realmente se pudieran haber introducido en el español, tienen que ser localizados en el uso libre del idioma español por parte de bilingües que hablaban los dos idiomas, español y árabe. Tales bilingües eran los mozárabes. Mi hipótesis es, entonces, que en la redacción de los Fueros de Salamanca y Zamora participaron mozárabes bilingües, los cuales introdujeron en el leonés antiguo, debido a interferencias con el árabe, la posposición del sujeto.

¿En qué se fundamenta la hipótesis de la (posible) participación de mozárabes en la elaboración de los Fueros de Salamanca y Zamora?

\subsubsection{Mozárabes en León.}

La presencia de mozárabes en León y su trascedencia en las particularidades culturales y lingüísticas del mismo ha sido tratado ya muchas veces en la bibliografía especializada en dicha materia (véase, por ejemplo, Menéndez Pidal, 1929, §§ 91-94). En términos generales, se puede decir que la repoblación del reino asturiano-leonés, que en gran parte estaba despoblado en el siglo viII, se efectuó con una numerosa participación de mozárabes ${ }^{7}$. De ello dan testimonio topónimos como Toldanos (al sudeste, cerca de León, así como a la orilla del río Araduey al nord-nordeste de $\mathrm{Za}$ -

i Véase J. Pérez de Urbel (1951, especialmente las págs. 157-162). Ya en la Crónica de Alfonso III se menciona el hecho de que se efectuara parte de la repoblación bajo el reinado de Ordoño I por emigrantes procedentes de "España", es decir, de tierra musulmana: "Partim ex suis, partim ex Spania advenientibus" (ed. por Z. G. Villada, 1918, pág. 127; aquí citado según Pérez de Urbel, 1951, pág. 157, nota 40). Véase también Sánchez Albornoz (1966, especialmente las págs. 266-269 y 357-362). Dice, entre otras cosas: "no puede dudarse del mozarabismo de esos arabizados pobladores del páramo leonés y de las tierras de Zamora y de Campos y no cabe asombrarse de que a veces ocuparan puestos de privilegio en la vida social y política del reino" (pág. 268). También Valdeón Baruque (1980) alude a la "Proyección del mozarabismo leonés" (pág. 17) en Salamanca. 
mora), Mozarbitos (al sur de Ledesma), Coreses (en las proximidades de Zamora, un poblado fundado por mozárabes de Coria). La presencia de mozárabes también está documentada en los fueros leoneses. El Fuero de Ledesma ( $\$ 2$, pág. 216, lin. 13) nombra otro poblado llamado Moçaraues. El Fuero de Salamanca ( $§ 271$, pág. 174, lín. 7 y $§ 291$, pág. 183, lín. 4) también menciona como grupo étnico propio, además de a los francos (de Aragón), portogaleses, serranos, castellanos y toreses, a los mozaraues. Mientras que la repoblación de León, efectuada en gran medida durante el siglo $x$, se realiza con una cuantiosa afluencia de mozárabes, que vienen del sur, la expansión norte-sur de Castilla está marcada por una migración en dirección contraria, es decir, del norte al sur. Por lo general, vale lo que dice Menéndez Pidal (Orígenes, 1929) sobre el desarrollo lingüístico relacionado con estos movimientos de repoblación: "Las ciudades y campos que estaban yermos hacía un siglo o dos (...) tenían que recibir como preponderante el habla de los restauradores del norte y del sur" (pág. 446). En lo concerniente a León, puede, por eso, afirmar Menéndez Pidal: “(es) predominante en nuestro período, sobre todo en el siglo $x$, la influencia árabe, sostenida principalmente por los mozárabes" (pág. 475). Esta influencia no solo se extiende, en un sentido estricto, sobre el idioma, sino que también afecta a las características de las instituciones, especialmente a las de ámbito jurídico. A diferencia del creciente condado de Castilla, la casa real asturiana-leonesa se consideraba como sucesora legítima del reino de los visigodos destruido por los árabes. Los mozárabes de Toledo aportaron al reino de León el Fuero Juzgo, código ya promulgado por los reyes visigodos, o versiones modificadas del mismo. El Fuero de Alba de Tormes (§ 3, pág. 292, lín. 20) alude al Tribunal del Libro (esto es el Fuero Juzgo) en León, que tiene la función de un tribunal de apelación. Acerca de eso escribe Menéndez Pidal (Orígenes, 1929): "El Fuero Juzgo, legislación de los mozárabes rechazada al principio por los repobladores castellanos, se fue generalizando para todos en el curso de los siglos XII y XIII; de modo que en el siglo XIV se distinguía en Toledo a los de fuera, que eran del reino de Castilla, en que no se regían por el Fuero Juzgo" (págs. 458 y sigs.).

A la vista de tantos factores histórico-culturales, no es, entonces, sorprendente el hecho de que el leonés comparta tantos rasgos comunes con el dialecto mozárabe; más bien, parece una covariable, que era de esperar. "El habla romance de los mozárabes toledanos, en los siglos XII y XIII (...) tenía varios rasgos comunes con el leonés (...), y eso no solo la del pueblo bajo, sino también la de los notables, como don Pedro Apolechén y su notario (DL, 2610) que en 1191 empleaban en sus escritos la $l l$ en vez de la $j$ " 
(Menéndez Pidal, Orígenes, 1929, págs. 457 y sigs.) ${ }^{8}$. Los rasgos comunes entre el mozárabe (el dialecto mozárabe toledano) y el leonés se pueden apreciar claramente (aparte del léxico) en la fonética y la fonología, campo investigado con profundidad. En cuanto a la sintaxis, la investigación no ha llegado a resultados concluyentes, $y$, por tanto, tampoco con respecto al orden de palabras. Pero, de todos modos, si partimos de las características comunes que, a nivel de fonética-fonología, comparten el leonés y el mozárabe, podemos, tal vez, extraer una posible influencia de características de la sintaxis mozárabe en la sintaxis del leonés. Por consiguiente, también puede haberse producido tal influencia en los autores de los fueros leoneses ${ }^{\circ}$.

\subsubsection{Los textos del español actual}

Como textos del español actual he analizado:

1) Un texto constituido de forma oral, en concreto la transcripción de una entrevista emitida por la radio (Antena 3, septiembre de 1983) de la serie "Usted pregunta", en la que es entrevistado José Luis de Vilallonga (de 42 folios escritos a máquina);

2) Un texto constituido de forma escrita, en concreto, la parte editorial entera (es decir, sin publicidad, sin anuncios, sin programas de radio y televisión) del periódico El País del 20 de enero de 1986.

\subsubsection{Los textos franceses}

De entre las lenguas románicas, de las cuales, al parecer, se distinguen el portugués y el español por la "frecuente" posposición del sujeto, he elegido el francés, y como texto del francés antiguo, a través del cual voy a llevar a cabo el análisis comparativo con los fueros, el coutumier "Le Livre des Droits de Verdun", el cual reune tres condiciones:

8 La afirmación de que el mozárabe del "pueblo bajo" de Toledo presentaba rasgos comunes con el leonés se basa, en realidad, en una conjetura, porque no existen autógrafos del "pueblo bajo" debido a su condición analfabeta. Esta conjetura (que indiscutiblemente es plausible) nace de la hipótesis que sostiene que el "desarrollo lingüistico", por regla general, empezaría, primeramente, a producirse en el "pueblo bajo", porque a éste le faltaría la conciencia lingüística que controla el uso del idioma produciendo un efecto conservador, conciencia, en cambio, típica del idioma a nivel culto. Ahora bien, la existencia de ejemplos que muestran un conservadurismo en el uso del idioma del tal llamado nivel bajo hacen dudar de esta hipótesis global.

- Lapesa (1963) menciona también la existencia de mozarabismos a nivel fonéticofonológico fuera de León, por ejemplo en el Fuero de Madrid, cuya redacción se terminó en el año 1202. Véase también Lapesa (1981, págs. 189 y sigs.). 
- se trata del mismo tipo que los fueros;

- su aparición se produce casi al mismo tiempo que la de los fueros (la presente versión del "Livre des Droits de Verdun" fue escrita alrededor del año 1340 , versiones previas se remontan hasta el año 1240);

- tine su origen en una región geográfica excluida de una posible influencia árabe.

El criterio utilizado para la selección de los textos del francés actual es análogo al criterio ya aplicado al español, es decir, hay un texto constituido de forma oral $y$ otro de forma escrita:

1) la transcripción de una discusión pública del año 1975 con el tema de "Le masque et la plume" transmitida por la radio francesa (de 60 folios escritos a máquina),

2) la parte editorial del diario Le Monde del 25 de enero de 1986.

\subsection{Los parámetros examinados}

Investigar, estadísticamente, la problemática de si en el español la posposición del sujeto se da con mayor frecuencia que en francés, supone una serie de consideraciones previas sobre los tipos de sujeto y el cómo han de ser contados. A primera vista debería de estar fuera de toda controversia la función de sujeto sintáctico que en los ejemplos (3) a (6) desempeñan los constituyentes puestos en letra bastardilla:

(3) Enrique Tierno Galván, el viejo profesor, falleció ayer (El Pais. 201-86).

(4) "Yo mismo", reconoció, "en un momento dado, he cometido excesos verbales..." (El Pais, 20-1-86).

(5) Tengo la esperanza de que esta carta sea la única que usted reciba (El Pais, 20-1-86).

(6) Cuentan los cronistas que uno de los mayores aislamientos de Gaddafi se produjo en 1982 (El Pais, 20-1-86).

En estos ejemplos clasificaríamos como sujetos antepuestos: 1. Enrique Tierno Galván...; 2. Yo; 3. esta carta; 4. usted; 5. uno de los mayores aislamientos de Gaddaffi; y como sujetos pospuestos: I. el morfema personal - $\delta$ en reconoció; 2 . el morfema personal -o en tengo; 3 . los cronistas. La valoración de los datos de este mini-corpus, efectuada a través de una 
simple adición, daría como resultado estadístico una proporción de 5 a 3 sujetos antepuestos a sujetos pospuestos respectivamente. Si este mini-corpus fuera representativo para el español de hoy, podriamos afirmar que el español actual tiene en un $37.5 \%$ de los casos el sujeto pospuesto y en un $62.5 \%$ el sujeto antepuesto. El problema de verificar si este $37.5 \%$ de sujetos pospuestos en español sobrepasa la frecuencia de sujetos pospuestos en francés, se solucionaría a través de la correspondiente evaluación de un corpus francés análogo. A primera vista, parece que no haya nada en contra de dejar el asunto así, sin hacer ninguna distinción entre diferentes tipos de sujeto. Procediendo de este modo, encontramos en el Fuero de Zamora 516 sujetos antepuestos y 813 sujetos pospuestos (véase tabla 1); esto equivale, aproximadamente, a una proporción de $40 \%$ de sujetos antepuestos a un $60 \%$ de sujetos pospuestos. ¿Estaría con este resultado comprobada, tanto en términos relativos como absolutos, la afirmación de Kuen? Evidentemente no.

Un cálculo global, sin diferenciar entre diferentes tipos de sujeto, no puede constituir, de ninguna forma, una base adecuada para el examen de la cuestión de si en español, en comparación con el francés, hay mayor frecuencia de la posposición del sujeto. Una de las razones, por las que hay que distinguir diferentes tipos de sujeto, nace de las diferencias estructurales que entre el español y el francés surgen a nivel de la morfología verbal. Mientras que en español, si no se toman en consideración algunas excepciones, como el subjuntivo y el imperfecto, los morfemas enclíticos personales marcan inequívocamente el sujeto respectivo, por ejemplo, cuento, cuentas, cuenta, etc., en el francés hablado la persona, o sea el sujeto, solamente se puede indicar por los pronombres personales, excepto en la primera y la segunda persona del plural, colocados delante o detrás del verbo, je compte, tu comptes, il compte, etc. En todo caso, raras veces aparecen en francés formas del tipo compte no complementadas con un pronombre personal antepuesto, mientras que la forma correspondiente en español, del tipo cuenta, se presenta, así, con alta frecuencia. Además, es de suponer que entre todas las formas verbales fuera la de la tercera persona del singular la de la más alta frecuencia relativa. La forma cuenta se clasifica como sujeto pospuesto, y la forma correspondiente en francés il compte como sujeto antepuesto. Por eso es, estadísticamente, previsible que en español haya un gran número de sujetos pospuestos así como en el francés de sujetos antepuestos. En efecto, de los 813 sujetos pospuestos, ya mencionados, que encontramos en el Fuero de Zamora nada menos que 476 corresponden al tipo de sujeto de cuenta ( $3 .^{a}$ persona del singular), esto es un $58.5 \%$. Por otro lado, 709 de $1.600(=44.3 \%)$ sujetos antepues- 
tos en el texto francés "Verdun" corresponden al tipo de sujeto de il compte (véase tabla 1).

Dicho de una manera general : sin diferenciar entre tipos de sujeto son justamente estos dos tipos de sujeto de cuenta y il compte los que nos llevan a observar un predominio de sujetos pospuestos en el español de los Fueros de Zamora y de Salamanca, y de sujetos antepuestos en el "Livre des Droits de Verdun".

Este resultado y, por consiguiente, el método empleado en la estadística son poco satisfactorios. De modo que vamos a volver otra vez a la teoría de Kuen. Sabemos que Kuen habló solamente de la anteposición del verbo, $y$, en cuanto a la posposición del sujeto implicada en ella, es muy poco probable que haya pensado en la posposición del sujeto en forma de morfema personal, como en el caso de cuenta. Cuando se trata de una anteposición del verbo y una posposición del sujeto, lo primero que se piensa es en sujetos con forma de sintagma nominal, como en los ejemplos (3) Enrique Tierno Galván, (5) esta carta, (6) los cronistas, etc. En todo caso, debe de ser nuestra finalidad, independientemente de todo tipo de especulación sobre qué tipo de sujeto pospuesto tenía a la vista Kuen, precisar la cuestión de tal manera que entren en el cálculo estadístico sólo aquellos tipos de sujeto, con respecto a los cuales se puede plantear, de alguna forma razonable, el problema de una influencia árabe. La hipótesis de la posposición de los sujetos, causada por influencia árabe, no la podemos referir a la posposición obligatoria de la terminación verbal determinada por la morfología del español, como se presenta en el tipo de sujeto de cuenta. Dicho de otra forma, se pueden examinar, con respecto a esta cuestión, solamente aquellos tipos de sujeto, para los cuales el hablante del castellano o del leonés tenía (o tiene) realmente una opción entre anteposición y posposición. Sólo en esta alternativa hubiera podido ejercer influencia el árabe sobre los hablantes del castellano o del leonés. Los tipos de sujeto a los que se puede aplicar esta restricción son los ya mencionados sintagmas nominales, como esta carta, los cronistas, etc., así como los pronombres personales, yo, él/ella, esta, ellos, etc., colocados delante o detrás del verbo. La misma restricción se aplica, de forma análoga, al francés, es decir, que se deben de tomar en consideración, por ejemplo, los pronombres personales "libres" (il, elle, ils, elles) pospuestos, etc. Resumiendo lo anteriormente expuesto, no cabe duda de la necesidad de distinguir, como datos estadísticos, los diferentes tipos de sujeto.

En concreto se examinan como parámetros los siguientes tipos de sujeto (cada tipo estructural se ilustra con un ejemplo en español antiguo, espaniol actual, francés antiguo y francés actual, en cuanto que se halle representado en los textos): 


\section{Sujetos antepuestos}

- Indice 11: sujeto (= sintagma nominal) + verbum finitum (=VF)

Ejemplos :

(1) Esta es postura que el conceyo de Camora puso que nengun omne nin nenguna mugier non (Zamora 61, 27/28).

(2) esa canción decía no vayas presumiendo (Vilallonga 2, 17).

(3) Se ung home marie son filz et adviengne qu'il lui donne en son mariaige une somme d'argent, et vient le pere si faict paiement a son filz ou a son genre de tant comme il lui oit convent au mariaige faire par le record des marieurs. (Verdun 33, 32-34).

(4) à mon sens. l'auteur de l'amendement est complètement ignorant (Le masque et la plume 9, 29).

- Indice 12: sujeto (=pronombre $1 .^{a}$ sing.) $+V F$

(5) E se dixier: "que diez annos ha que yo essa herdade ey, e non me prindastes nen me tenptestes e fuestes enna tierra" (Zamora 28, 4-6).

(6) "Yo mismo", reconoció, "en un momento dado, he cometido excesos verbales..." (El Pais, pág. 14).

(7) "Sire, voire fust que je maria mon filz ou ma fille et lui donnai en mariaige une telle somme d'argent et bien le sceivent li marieurs qui au mariaige estoit" (Verdun 34, 4-6).

(8) Je ne viens pas conquérir le Berry avec des armes (Le Monde, pág. 10).

- Indice 13: sujcto (=promombre 2. ${ }^{a}$ sing.) $+V F$

(no parece representado en los textos analizados del español antiguo)

(9) los nombres tú da los que tú quieras (Vilallonga 41, 24).

(10) euh toi tu as donc quelqu'un qui est contre (Le masque et la plume 4,32 ).

- Indice 14: sujeto (=pronombre $3 .^{a}$ sing.) $+V F$

(11) Si algun ric'omne o cavallero fiziere fuerça en término de Sepúlvega, y alguno lo firiere o lo matare sobr'ello, non peche por ende calonna ninguna (Sepúlveda 62, 16-18).

(12) eso forma parte de mi curriculum (Vilallonga 2, 35).

(13) Véase (3).

(14) Jacques Chirac a un truc: quand il faut sourire et qu'il est triste, il dit à haute voix: 《Quistiti.» (Le Monde, pág. 8).

(14A) C'est pas une histoire c'est pas du film réaliste c'est une sorte de mise en scène (Le masque et la plume 22, 6). 
- Indice 15: sujeto (=pronombre 1.a pl.) $+V F$

(no aparece representado en los textos analizados del español antiguo).

(15) nosotros vamos a dar el teléfono (Vilallonga 4, 2).

(16) Voirs, Sire (ms. sur), que je clammai sur Jacommet au premier, quant nous eusmes nos emparliers prins. (Verdum 55, 14/15).

(17) Nous parlons la même langue, nous pratiquons le même islam (Le Monde, pág. 3).

- Indice 16: sujeto (=pronombre 2.a pl.) $+V F$

(no aparece representado ni en los textos analizados del español antiguo ni en los del español actual).

(18) "Sire, vous me debyés tant, si le vous demande, et s'en veult avoir l'amende" (Verdun 46, 9/10).

(19) elle demande pourquoi vous ne parlez jamais des courts métrages (Le masque et la plume 3,18 ).

- Indice 17: sujeto (=pronombre $3 .^{a}$ pl.) $+V F$

(20) Et si fijos varones ovieren, aquellos hereden todas las armas (Sepúlveda $88,21 / 22)$.

(21) pero ellos sí que sacan a veces (Vilallonga 29, 11).

(22) Or vient la justice, si leurs demande s'i vueillent ouir droit, selond ce que chascun ait dit, et il diënt oui (Verdun 49, 30/31).

(23) Instruits par l'expérience, ils craignent que, si cet «idéologue borné» revient aux affaires, ... (Le Monde, pág. 3).

- Indice 18: sujeto (= pronombre "usted") +VF

(no aparece representado en los textos analizados del español antiguo).

(24) usted bueno se mete bastante con la aristocracia (Vilallonga 12, 21).

- Indice 19: sujeto (= pronombre relativo) $+V F$

(25) Omne que aotro omne ferir, uaya el ferido odemuestre elas feridas abonos omnes (Zamora 18, 12/13).

(26) la persona que más miedo me ha dado fue (Vilallonga 11, 29).

(27) S'un homme git au lit de la mort qui aiet sa femme et ses enfans, (...) et il faict sa devise et son testament en son droit (Verdun 56, 10 y 11). 
(28) C'est le pont (de droite) qui a reçu l'aval de M. Fabius (Le Monde, página 9).

- Indice 110: sujeto (=pronombre relativo del plural) $+V F$

(29) Aprimas do e otorgo a los que moran en Sepúlvega y a los que son por venir Sepúlvega con todo su término (Sepúlveda 61, 29/30).

(30) la mayor parte de los extranjeros salieron de Aden en alguno de los cinco buques soviéticos que participaron en las faenas (El Pais, pág. 3).

(31) Véase (7).

(32) il y a ces deux femmes qui représentent l'espoir positif de cette génération (Le masque et la plume 50,7 ).

- Indice 111: sujeto (=pronombre interrogativo sing./pl.) $+V F$

(33) Oueyas que entraren en uinas uendimiadas, quienas hy tomar, prenda un carnero de los meyores quehy andaren, enon respondan por el (Zamora 43, 5-7).

(34) quienes son estos reyes que conoce (Vilallonga 7, 7).

(35) Et quil c'onques aramirait loi de povreté, le doien en pranrait la loi et le ferait savoir aulx maistre des vingt (Verdun 44, 1/2).

(36) Qui l'emportera des modérés ou des durs du parti? (Le Monde, pág. 3).

- Indice 112: sujeto (=oración) + VF

(no aparece representado ni en los textos analizados del español ni en el del francés antiguo).

(37) Que ces clans mettent un tel acharnement à s'exterminer dépasse l'entendement des diplomates (Le Monde, pág. 3).

- Indice 113: sujeto (=oración de infinitivo) + VF

(no aparece representado en los textos analizados del español antiguo).

(38) ser aparte (...) es (..) frustrante (Vilallonga 4, 23).

(39) [Expresar por escrito las sensaciones que se vehiculan a través de otro lenguaje es muy difícil. (El País, pág. 30)].

(no aparece representado en el texto analizado del francés antiguo).

(40) Faire voter de nouvelles réformes serait certainement pratiquement impossible (Le Monde, pág. 8). 
II. Sujetos pospuestos

- Indice 21: verbum finitum + sujeto (= sintagma nominal)

(41) Aqueste es el fuero e establecimiento que puso el conceyo de Camora que ualga por sienpre yamas (Zamora 60,5/6).

(42) un teléfono que ya conocen todos nuestros oyentes (Vilallonga 4, 4).

(43) Véase (3).

(44) j'suis tout à fait d'accord avec ce qu'a dit Michel Ciment (Le masque et la plume 22, 22).

- Indice 22: verbum finitum + sujeto (= pronombre 1. ${ }^{a}$ sing.)

(no aparece representado en los textos analizados del español antiguo).

(45) ahora soy yo quien le da las buenas tardes (Vilallonga 2, 11).

(46) "Sire, plaidiré-vous hui"? et le doien: "Ouir, vraiment plaidirai-je" (Verdun 41, 27/28).

(47) est-ce disais-je à cause de sa couleur politique (Le masque et la plume $7,1)$.

- Indice 23: verdum finitum + sujeto (= pronombre 2. ${ }^{a}$ sing.)

(no aparece representado en los textos analizados del español antiguo).

(48) pues me dicen bueno mira tú haz como eres tú (Vilallonga 12, 18).

(no aparece representado en los textos analizados del francés).

- Indice 24: $V F+$ sujeto (= pronombre $3 .^{a}$ sing.)

(49) Otrossí, todo omne que casas entrare por fuerça, et provárgelo pudieren con tres vezinos, y por quanto iurare, con los dos vezinos, aquél que reçibió el danno, péchelo el que fizo la fuerça (Sepúlveda 94, 20/21-95, 1/2).

(50) un monstruo que hay con un ojo efectivamente existe eso (Vilallonga $37,19)$.

(51) Mais se ung homne [se] lait embanir pour larencin ou pour murtre (ms. mustre) ou pour aultre (chose) desloiaulté, ceulx doit il pranre (Verdun $31,29 / 30$ ).

(52) mais pourquoi a-t-on donné le rôle à mademoiselle d'une telle (Le masque et la plume $23,28-30$ ). 
- Indice 25: $V F+$ sujeto (=pronombre $10^{a} \mathrm{pl}$.)

(no aparece representado en los textos analizados del español).

(53) Et toutes ses choses devant dites avons nous jurés tous a tenir en bonnes foi a nostre seigneur evesque (Verdun 58, 14/15).

(54) pourquoi, en France, ne ferions-nous pas également un geste en ce sens? (Le Monde, pág. 2).

- Indice 25a: VF + sujeto (= pronombre 2.a pl.)

(no aparece representado en los textos analizados del español).

(55) "Sire, qui distes-vous qui fut a cest paiemant que vous distes que vous m'avés fait?" (Verdun 53, 22/23).

(56) voulez-vous que nous commencions cette émission (Le masque et la plume 15,26$)$.

- Indice 26: $V F+$ sujeto (= pronombre $30^{\circ} \mathrm{pl}$ )

(57) E otrossi peichen eles alos herederos selos elos feriren (Zamora 51, 5).

(58) $\mathrm{Y}$ las relaciones que los sefardíes cuyas raíces están en el mundo islámico tienen con los judios procedentes de ese vasto orbe, aunque nada tengan éstos que ver con España (El País, pág. 13).

(59) que celle eschette qu'i tieinnont leur vient de leurs taion et que leur pere $n$ 'i oit oncques rien, ne de rien ne fust oncques tenus ne riens n'i avoit au jour que fust mort, s'en vouellent il desmoreir en paix, ne rien n'en veullent paier et bien en oiront droit (Verdun 36, 5-8).

(60) Nos deux premières communautés ne pourraient-elles pas cohabiter (Le Monde, pág. 2).

- Indice 27: VF + sujeto (= "usted")

(no aparece representado en los textos del español antiguo).

(61) si entonces ya nació en el veinte no tiene usted todavía sesenta y tres (Vilallonga 31, 17/18).

(no existe en el francés).

- Indice 28: VF + sujeto (=oración)

(no aparece representado en los textos analizados del español antiguo).

(62) le molesta a José Luis Vilallonga que se le ponga esa coletilla de aristócrata (Vilallonga 3, 22/23). 
(63) La dame respond et dit que voire fust que ses maris fist (ms. fust) acquestes ou temps de la premiere femme (Verdun 33, 14/15).

(64) Il est vrai qu'elle aurait aussi voté la résolution marocaine (Le Monde, pág. 4).

- Indice 29: $V F+$ sujeto (=oración de infinitivo)

(no aparece representado en los textos analizados del español antiguo).

(65) en el fondo me parece perfectamente inútil pues ponerme esa coletilla (Vilallonga 3, 24-26).

(no aparece representado en el texto analizado del francés antiguo).

(66) il ne nous appartient pas de discuter ces circonstances (Le masque et la plume 7,31 ).

- Indice 210: VF + sujeto (=morfema personal $1 .^{a}$ sing.)

(67) E se dixier el que demanda: "ant de diez annos passassen, demandei e prindei y aiuyzey", firme con .v. omnes bonos (Zamora 28, 6-8).

(68) no reniego de ello en absoluto (Vilallonga 4, 30).

(69) Véase (7).

(no aparece representado en los textos analizados del francés actual).

- Indice 211: $V F+$ sujeto (= morfema personal 2.a sing.)

(70) e se el otro dixier: "¿ non me canbiaras estos?" (Zamora 35, 5).

(71) ya he visto que no lo [el libro] has leído (Vilallonga 30, 5-7).

(no aparece representado en el texto analizado del francés antiguo).

(72) c'est pas la peine de nous écrire là aussi tiens je vais ajouter un petit postscriptum (Le masque et la plume 6, 9).

- Indice 212: $V F+$ sujeto (=morfema personal $3 .^{a}$ sing.)

(73) E se por el otro ficar que non quisier conplir derecho, prindenno cada dia ata que uenga aderecho (Zamora 40, 4/5).

(74) Combatió en la guerra civil en el lado republicano y estuvo internado en un campo de concentración (El País, pág. 1).

(75) Véase (3).

(76) M. Jack Lang réprime consciensement ses baillements, tente avec application rendre un peu de bouffant à ses boucles (Le Monde, pág. 10). 
- Indice 213: $V F+$ sujeto (= morfema personal $1 .^{a} \mathrm{pl}$.)

(77) Otrossi, por fazer bien y merçet al conceio de Sepúlvega, damos y otorgámosles que ayan los montadgos de los ganados que entraren por sus términos (Sepúlveda 63, 3-5).

(78) De allí marchamos a pie, ..., a la Embajada británica, desde donde fuimos llevados (...) a la playa (El Pais, pág. 3).

(79) Aprés [vous dison] s'aulcun homme faict semonre ung aultre, soit de dehors, soit bourgeois (Verdun 43, 23/24).

(80) qu'un certain public le souhaite laissons-le aller voir ces films (Le masque et la plume 11, 15).

- Indice 213a: verbum finitum + sujeto (=morfema personal $2 .^{a} \mathrm{pl.}$ )

(81) ¿quales son elos obreyros con que queredes conprir derecho? (Zamora $35,3 / 4)$.

(82) le visconte ne le peult mie prendre, ains doit venir au doien, et si lui doit dire: "J'ai tant d'ambanis; faict les prendre avecque les vostres" (Verdun 31,26$)$.

(83) ne nous écrivez pas pour nous dire (Le masque et la plume 6, 10).

- Indice 214: $V F+$ sujeto (=morfema personal 3.9 pl.)

(84) Véase (73).

(84) es una clase social que cuando tenían mucho dinero y tenían el poder político representaban algo pero hoy (Vilallonga 35, 5-8).

(86) Véase (59).

(87) les partisans du chef de l'Etat ont indiqué qu'ils ont «répondu positivement à la demande des camarades soviétiques» et demandent au camp adverse de «suivre leur exemple» (Le Monde, pág. 3).

\section{LOS RESULTADOS DEL ANÁLISIS ESTADÍSTICO Y SU INTERPRETACIÓN}

\subsection{La estadística}

Los resultados numéricos del análisis de los textos están contenidos en las tablas 1, 2 y siguientes. La tabla 1 comprende detalladamente la "frecuencia de los diferentes tipos de sujetos" que se da en los textos analizados (véase la lista de los parámetros explicados en la parte 3.2.). La tabla 2 muestra las "frecuencias conjuntas de determinados tipos de sujeto". El número total de los sujetos analizados (véase la columna "Suma de los 


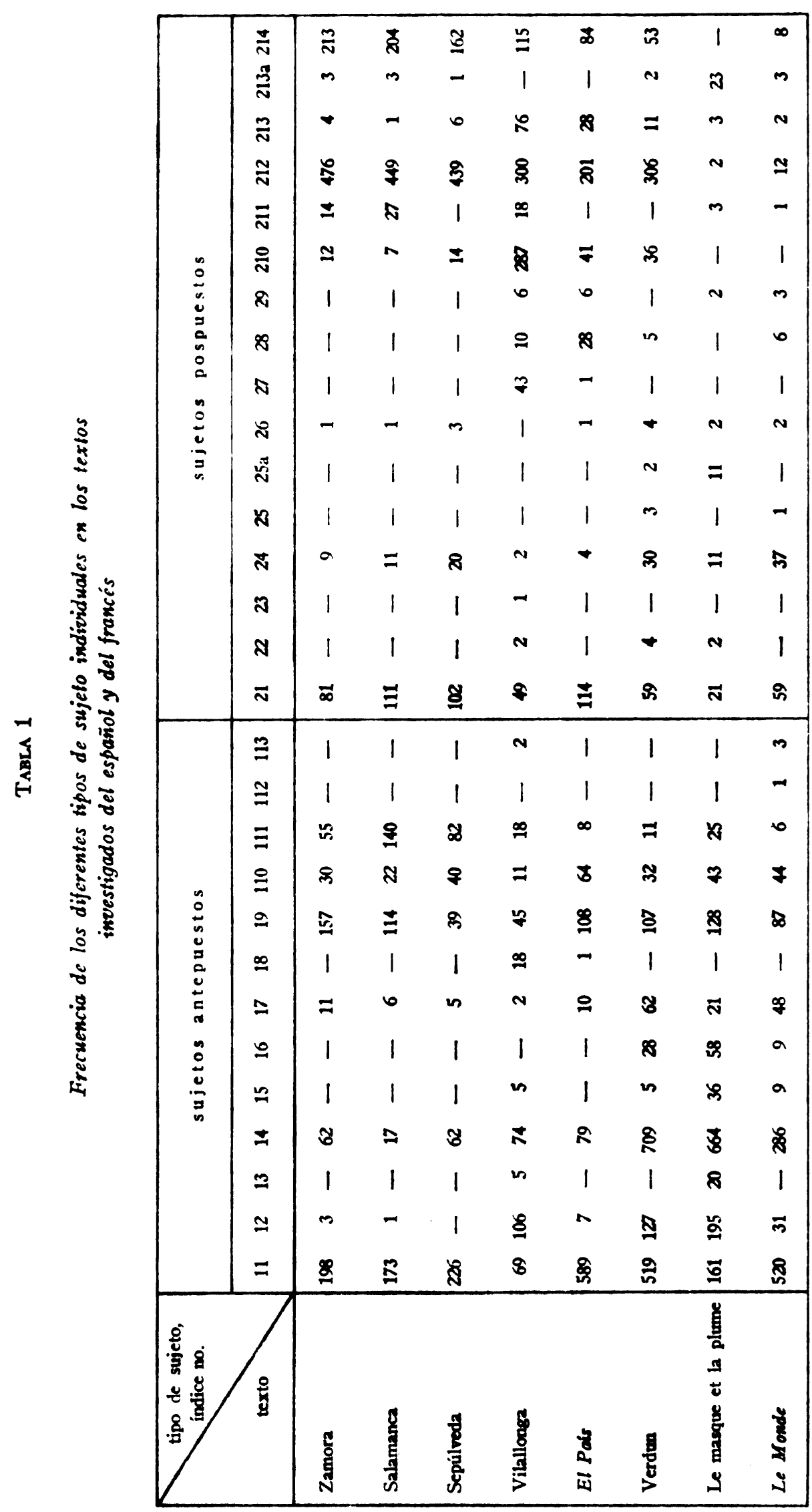


sujetos correspondientes a los tipos 11-214" de la tabla 2) es, esencialmente, igual en los diferentes textos, a excepción del texto de Verdun. La mayor proporción de este texto la he elegido expresamente para, comparándolo con los textos españoles, disminuir el riesgo de una distribución casual.

Las indicaciones porcentuales de las columnas 2 y 3 de la tabla 2 se refieren al número total correspondiente de sujetos analizados indicado en la columna 1 de la misma tabla. Las indicaciones porcentuales que aparecen detrás de cada número en las columnas 5 y 6 se refieren a la frecuencia conjunta de los sujetos de los tipos 11 y 21 indicada en la columna 4.

\section{TABla 2}

Frecuencias conjuntas de determinados tipos de sujeto en los textos analizados del español $y$ del francés

\begin{tabular}{|c|c|c|c|c|c|c|}
\hline \multirow{3}{*}{ (Columna) } & 1 & 2 & 3 & 4 & 5 & 6 \\
\hline & \multicolumn{4}{|c|}{$\begin{array}{c}\text { S U M A } \\
\text { de los sujetos correspondientes a los tipos }\end{array}$} & \multicolumn{2}{|c|}{$\begin{array}{l}\text { F R E C UE N C I A } \\
\text { de los sujetos del tipo }\end{array}$} \\
\hline & $11-214$ & $11-113$ & $21-214$ & 11 y 21 & $11(\%)$ & $21 \quad(\%)$ \\
\hline $\begin{array}{l}\text { Zamora } \\
\text { Salamanca } \\
\text { Sepúlveda } \\
\text { Vilallonga } \\
\text { El País }\end{array}$ & $\begin{array}{l}1329 \\
1337 \\
1201 \\
1265 \\
1374\end{array}$ & $\begin{array}{l}516(38.8 \%) \\
473(35.4 \%) \\
454(37.8 \%) \\
355(28.1 \%) \\
866(63.0 \%)\end{array}$ & $\begin{array}{l}813(61.2 \%) \\
864(64.6 \%) \\
747(62.2 \%) \\
910(71.9 \%) \\
508(37.0 \%)\end{array}$ & $\begin{array}{l}279 \\
284 \\
328 \\
118 \\
703\end{array}$ & $\begin{array}{r}198(71.0) \\
173(60.9) \\
226(69.0) \\
69(58.5) \\
589(83.8)\end{array}$ & $\begin{aligned} 81 & (29.0) \\
111 & (39.1) \\
102 & (31.0) \\
49 & (41.5) \\
114 & (16.2)\end{aligned}$ \\
\hline $\begin{array}{l}\text { Verdun } \\
\text { Le masque et la plume } \\
\text { Le Monde }\end{array}$ & $\begin{array}{l}2115 \\
1431 \\
1178\end{array}$ & $\begin{array}{l}1600(75.6 \%) \\
1351(94.4 \%) \\
1044(88.6 \%)\end{array}$ & $\begin{array}{r}515(24.4 \%) \\
80(5.6 \%) \\
134(11.4 \%)\end{array}$ & $\begin{array}{l}578 \\
183 \\
579\end{array}$ & $\begin{array}{l}519(90.0) \\
161(88.0) \\
520(90.0)\end{array}$ & $\begin{array}{l}59(10.0) \\
21(12.0) \\
59(10.0)\end{array}$ \\
\hline
\end{tabular}

Así resulta, por ejemplo, que de los 1.337 sujetos contados en el Fuero de Salamanca (analizado hasta el $\S 180$ inclusive) 473 (= $35.38 \%$ ) son sujetos antepuestos y $864(=64.62 \%)$ sujetos pospuestos (véase, sin embargo, la interpretación de estos datos que se da en la parte 4.2.). Si solamente se cuentan los sujetos en forma de sintagma nominal, marcados por los índices 11 y 21 (véase la columna 4 de la tabla 2), se obtiene como resultado que en el Fuero de Zamora el 71\% (véase columna 5) corresponde al tipo de sujetos antepuestos y el $29 \%$ (véase columna 6) al tipo 21 de sujetos pospuestos. 


\subsection{La interpretación de la estadistica}

Uno de los resultados más evidentes de este análisis, quizás el más importante de todos, consiste en que el predominio de la anteposición o de la posposición del sujeto depende de los tipos de sujeto que se toman en consideración. Si se compara, en los textos españoles, la suma de todos los sujetos antepuestos con la de todos los sujetos pospuestos, nos encontramos con que solamente en El Pais hay un predominio de los sujetos antepuestos, que asciende al $63 \%$, mientras que es en el español hablado donde los sujetos pospuestos alcanzan el mayor porcentaje, un $71.9 \%$, como así se demuestra en la entrevista radiofónica mantenida con Vilallonga. Frente a esto, y según el cálculo global de los sujetos, prevalece claramente la anteposición en todos los textos franceses, con mayor frecuencia en el francés hablado de "Le masque et la plume", un $94.4 \%$.

Ya en la parte 3.2. he explicado que el cálculo global de sujetos no puede ser un método adecuado para el examen de la hipótesis que sostiene una posible influencia árabe en la posición del sujeto español. Tenemos, por consiguiente, que excluir del análisis aquellos tipos de sujetos que no han podido ser alcanzados por una influencia árabe, como son, en primer lugar, las terminaciones de la conjugación española, porque están fuera de la opción del hablante, $y$, por la misma razón, tenemos que excluir, en francés, los pronombres personales antepuestos. Volvamos a examinar el ejemplo de los 813 sujetos pospuestos del Fuero de Zamora (véase columna 3, tabla 2). De ellos nada menos que 689 , es decir, un $84 \%$, corresponden a los tipos de sujeto representados con los indices 212 y 214 , y sólo 81 (véase tabla 1), es decir, el $10 \%$, corresponden a los sujetos en forma de sintagma nominal, como en este tipo de expresiones: un teléfono que ya conocen todos "nuestros oyentes". Sólo en la posición de este $10 \%$ de los sujetos pospuestos así como en el $38.3 \%$ (=198) de los sujetos antepuestos, es decir, sólo en la posición de un $21 \%$ de todos los sujetos del Fuero de Zamora, hubiera podido ejercer influencia el árabe. Por eso, aludiré. en el marco de este estudio, preferentemente, a los tipos de sujetos marcados con los indices 11 y 12 .

He aquí los resultados más importantes:

1) En todos los textos españoles predomina la anteposición del sujeto. A la cabeza está situado el español moderno escrito de El País con un 83.8\%. Cierra la escala el español hablado de hoy con un $58 \%$. Es cierto, que el número absoluto de los sujetos en forma de sintagma nominal encontrados en el español hablado es relativamente pequeño, sólo llega a 119 
(véase la columna 4 de la tabla 2). Antes de llegar a la conclusión de que en el español hablado se da una tendencia a la posposición de los sujetos, se debería de examinar un corpus más amplio.

2) Entre los Fueros de Zamora $(71 \%)$ y Salamanca $(60.9 \%)$, por un lado, y el de Sepúlveda (69\%), por otro, no existen diferencias relevantes. $\mathrm{Ni}$ siquiera se puede reconocer por los datos recogidos una tendencia que indicara, por ejemplo, que en los dos fueros leoneses la anteposición del sujeto se diera en un número claramente inferior al del fuero castellano de Sepúlveda. Por tanto, queda sin comprobar la hipótesis que precisamente sirvió de base para la selección de estos fueros, la cual mantenía que en los Fueros de Zamora y Salamanca podrian encontrarse más sujetos pospuestos que en el de Sepúlveda, a causa de una posible influencia mozárabe en su relación.

Este resultado induce a suponer que en el español no ha influido el árabe en la posición del sujeto. Dicha conclusión, como se verá más adelante, está respaldada por la interpretación de los datos obtenidos del francés.

3) En los textos franceses, se observa que los sujetos están colocados con una gran homogeneidad. Alrededor de un $90 \%$ se encuentran delante del verbo.

4) Resumiendo lo hasta ahora expuesto, se puede decir que, en términos relativos, el español emplea con mayor frecuencia el sujeto pospuesto que el francés (25\% a 10\%), predominando, en térninos absolutos, la anteposición en ambos idiomas.

Esto, por cierto, es sólo un resultado provisional. Si se observa con más detenimiento el francés, resulta sorprendente que aparezcan tan frecuentemente sujetos pospuestos en una lengua románica, que ni siquiera ha estado expuesta a la más mínima influencia árabe. Si afirmamos que la posposición del sujeto es un recurso genuino y común a todas las lenguas románicas $^{10}$, ¿ cómo se puede explicar, entonces, la mayor frecuencia relativa con la que aparece en español la posposición del sujeto, teniendo en cuenta que los dos idiomas (francés y español) son, desde los tiempos antiguos, claramente lenguas del tipo SVO?

$\mathrm{Si}, \mathrm{y}$ en relación con lo anteriormente dicho, miramos más detenidamente las condiciones contextuales de los sujetos del tipo 21 (véase como manda este libro), parece mostrarse que en el español, tal como aparece en

10 Véase, respecto a ello, la observación de Maupas (1625): "Nostre langue aime à suivre en l'arrangement de nos mots l'ordre naturel de l'entendement, qui est que la diction regissant soit devant la regie (...). Qui est cause qu'elle ne permet un tel meslange \& entrelacement de paroles comme la latine \& quelque autres" (pág. 25). 
los textos analizados, rigen menos restricciones contextuales que en el francés moderno, ya sea hablado o escrito. Tanto en "Le masque et la plume" (francés hablado) como en Le Monde (francés escrito), se presentan los sujetos del tipo 21 , en un $85 \%$ de los casos aproximadamente, en contextos de verbos de comunicación, o sea, "verba dicendi", es decir, en frases como raconte l'ambassadeur, souligne $M$. Audebert, écrit la Pravda, comme le préconise lopposition, etc. ${ }^{11}$. El $15 \%$ restante se distribuye, sobre todo, entre oraciones subordinadas, como les problemes constitutionnels que soulève la cohabitation, así como entre oraciones interrogativas, como comment sort ce genre de films, etc.

Estas restricciones contextuales no parecen regir en el español, al menos no en los textos analizados. He aquí, como ejemplos, los primeros sujetos pospuestos de El País (20-1-86), por orden de su aparición:

- desaparece uno de los protagonistas

- queda un difícil camino por recorrer

- proseguian los enfrentamientos

También aparecen, por supuesto, los sujetos pospuestos del tipo 21 en el contexto de verbos de comunicación:

- informó la agencia soviética Tass

- según dijo la radio noryemeni

- adonde llegó ayer el lider

- cantó Thomas

- aún queda en la capital suryemeni un millar de extranjeros

- dijo el testigo

- donde nació el hoy lider libio

- de esta tribu ha salido el guía de la revolución

- púlpito desde el que predicaba Luther King

etcétera.

Se podría mostrar, con ejemplos sacados de otros textos españoles, que las restricciones contextuales, semánticas y sintácticas, que valen para la posposición del sujeto en el francés moderno, no parecen regir en el espa-

11 Extraña que Le Bidois (1941) no dedique ni una sola palabra a este tipo de construcciones o contextos en los que aparece la posposición del sujeto. Le Bidois, en cambio, enumera "Verbes introduisant une indication de temps". "Le verbe 'suivre'", "Verbes de mouvement", "Le verbe est accompagné d'un adverbe de liaison", "Le verbe 'rester'", etc. 
ñol ${ }^{12}$. De modo que la mayor frecuencia relativa de la posposición del sujeto en español se debería de considerar como corolario de las restricciones contextuales descritas para el francés.

Ahora bien, ¿es debido a una influencia árabe el hecho de que en el español no valgan las restricciones contextuales estrictas que se pueden registrar en el francés?

Bajo esta perspectiva, examinemos los textos en francés antiguo: en el "Livre des Droits de Verdun" no parecen regir las restricciones contextuales registradas en el francés moderno:

- il faissiënt acquest emsemble, le mari et la femme

- ne le doit pranre aultre que lui

- que ainci dit Droit

- après que celle femme se muert et demeure le mari et les enfants

- Or vont les enfants de la première femme

- et vient le pere si faict paiement à son filz

- et bien le sceivent li marieurs qui au mariaige estoit

- Dont vient les freres ou les seures

- Or viennent les debteurs

[Pero también: Le Droit dit]

- comme acquestz et en doient avoir les enfants la moitié

etcétera.

Suponiendo que los textos analizados del español antiguo y del francés antiguo nos permitan llegar a conclusiones generalizadas, podemos declarar

12 En cuanto al español, el trabajo de Morales de Walters (1982) es, hasta ahora, el único que, empíricamente, analiza la posición del sujeto en relación a la clase semántica verbal. De los 1.529 verbos analizados únicamente 56 pertenecen a la clase llamada "verbos de expresión" (decir, declarar, etc.), o sea, "verbos de comunicación". De estos 56 casos de "verbos de expresión" son sujetos antepuestos 51 casos, es decir, un $91.07 \%$. Cinco $(=8.92 \%)$ son sujetos pospuestos.

Entre las diez clases verbales hay únicamente dos en las que Morales de Walters puede constatar una frecuencia mayor de los sujetos pospuestos, es decir, los. "verbos intransitivos de tipo estático como: aparecer, contimuar (...)" (pág. 26), verbos estos que corresponden, a grandes rasgos, a los llamados verbos presentativos, con una distribución de $27.38 \%$ y $72.62 \%$ de sujetos ante- y pospuestos respectivamente, además los "verbos de reacción psicológica generalmente con sujeto oracional (...) aterrar, gustar (...) verbos de duda: ser probable (...) y de opinión: parecer, resultar, etc." (página 26). Esta clase - yo prescindo de una discusión de la clasificación- demuestra el mayor porcentaje de sujetos pospuestos, es decir, un $87.71 \%$ y sólo $12.28 \%$ de sujetos antepuestos. De los 1.526 sujetos analizados son pospuestos: 298, o sea, un 19.5\%.

Aunque Morales de Walters incluye en su censo tipos de sujetos que yo no he tenido en cuenta, como, por ejemplo, los llamados presentativos, las estadísticas no muestran resultados con diferencias significativas. 
que no han existido entre ellos diferencias en lo relativo a las restricciones contextuales para el uso de sujetos pospuestos del tipo 21. A este respecto, el español moderno no ha experimentado un cambio esencial frente al español antiguo; es el francés moderno, en cambio, donde se encuentran estructuras distintas, tanto en su constitución hablada como en la escrita.

Del hecho de que en el francés antiguo rigieran restricciones contextuales parecidas a las del español antiguo para el uso de sujetos pospuestos se puede deducir que las restricciones contextuales "blandas" del español no se pueden atribuir a una influencia árabe.

Siguiendo esta argumentación ${ }^{13}$, habría que centrarse en el francés, y no en el español, cuando se trata de explicar la posposición del sujeto. Los datos recogidos señalan un desarrollo, durante el cual el francés se ha ido alejando de una estructura que en la Edad Media todavía compartía con el español, y que en éste se conserva. La pregunta es, entonces, ¿cuándo y por qué cambiaron en el francés las restricciones contextuales para el uso de sujetos pospuestos? ${ }^{14}$. Pero investigar esta problemática debe quedar como objetivo de un trabajo futuro.

13 El presente estudio es de un carácter meramente explorativo en cuanto a la fundamentación estadística relativa al francés. Para obtener datos más fiables ha de investigarse una mayor cantidad de textos $y$ distinguir entre diferentes tipos de contexto.

14 La comprobación de diferencias considerables existentes entre el francés antiguo y el moderno en relación al orden de los constituyentes $\mathrm{S}, \mathrm{V}$ y $\mathrm{O}$, de tal manera que el francés moderno ha perdido la "libertad" que disfrutaba el francés antiguo, no es en absoluto un hallazgo nuevo (véase también la nota 10). Dice, por ejemplo, Foulet (1930): "L'ancien français, nous le savons, entraine les mots avec une liberté qui est inconnue à la langue moderne" (pág. 306). Foulet distingue entre las cuatro construcciones siguientes: a) sujeto-verbo-objeto, b) $\mathrm{S}-\mathrm{O}-\mathrm{V}$, c) V-S-O, y d) O-V-S (véase pág. 306), de las cuales, salvo algunas excepciones, sólo la primera se ha conservado en el francés moderno. Acerca de esa construcción SVO explica Foulet: "Dès le moyen âge, c'est une construction favorite de la langue" (pág. 318). Desgraciadamente, no ofrece Foulet datos más exactos sobre la frecuencia de las cuatro construcciones mencionadas en el francés antiguo. La lista más detallada sobre el orden de los constituyentes $\mathrm{S}, \mathrm{V}$ y $\mathrm{O}$ en los diferentes contextos en el francés escrito la da Blinkenberg (1958, págs. 76-152). A estos contextos pertenecen, por ejemplo, los "verbes de mouvement", etc. Pero, desgraciadamente, esa lista no nos da la clave para la distribución estadística entre los diferentes tipos de contextos.

Algunas de las innumerables investigaciones que sobre el orden de palabras en el francés antiguo, medio y moderno existen están completadas con amplias estadísticas, pero, por regla general, no son comparables, o sólo lo son parcialmente, con los datos de mi estadística, porque emplean parámetros diferentes. En este contexto habria que mencionar los trabajos de Wespy (1884), Le Bidois (1941), Muller (1942), Nissen (1943), Lewinsky (1949), Price (1961), Rickard (1962), Clifford (1973) y Lerch (1934), etc. Según Clifford (1973, pág. 3), Wespy (1884) ya había observado el "gradual decline of the proportion of main clauses with inverted order in the course of the Middle Ages". Sobre ciertas restricciones estructurales para la inversión que surgen en el siglo XVII ya ha tratado Antoine (1958). Para él los adverbios sólo ocasionan 


\section{RESUMEN}

- El español y el francés son, inequívocamente, lenguas del tipo SVO, ya desde los tiempos de su formación, y no lo son como resultado de una evolución reciente (como así lo supone Givón, 1983, pág. 33, respecto al español) ${ }^{15}$.

- En el español se presentan sujetos pospuestos con mayor frecuencia relativa que en el francés (en el español un $25 \%$, en el francés alrededor de un $10 \%$ del total de los sujetos en forma de sintagma nominal).

- La frecuencia relativa de los sujetos pospuestos en el español es un corolario de las estrictas restricciones contextuales que rigen la posposición del sujeto en el francés moderno.

- En cuanto a las restricciones contextuales para los sujetos pospuestos del tipo 21 no hay diferencias entre el español antiguo y el francés antiguo.

la inversión cuando establecen un enlace temático con la frase anterior. Rickard (1962) aborda, entre otras cosas, la cuestión de si pudiera haber existido una relación causaefecto entre el desarrollo del orden de palabras que ha conducido a la fijeza existente en el francés moderno y la paulatina desaparición del sistema bicasual que antes tenía el francés, porque la marcación de los dos casos permitía un orden más libre entre los constituyentes. Pero, para esta conjetura, no existen pruebas. Más bien, parece demostrar lo contrario el hecho de que el sistema bicasual tampoco sostuviese una oposición completa entre los casos, "since feminine nouns were for the most part as invariable as they are today" (pág. 3). Además, según Rickard, ya en los tiempos del sistema bicasual predominaba el orden SVO (¿ Pero dónde están las estadísticas concluyentes?) (véase Rickard, 1962, págs. 2 y sigs.).

$15 \mathrm{Ni}$ siquiera hay claridad en la estructura del español de hoy, así lo demuestran las siguientes afirmaciones globales de Wright (1983); dice: "there is also now emerging a strong preference for verb-initial clauses, particularly with verbs of motion (llegó el tren [...]) and in relative clauses (la casa en que dejó sus cuadros Picasso [...]). This is all uncontroversial [sic]" (págs. 4 y sigs.). ¿Pero dónde están -hay que preguntar de nuevo- las estadísticas que comprueben esas afirmaciones? Wright (1983) sigue: "Spanish is among other things developing the potential for functionally free word order" (pág. 15). Pero parece que, en ciertas partes del mundo hispanohablante, se está desarrollando una tendencia hacia la predeterminación (la cual reclama Wright para el francés, véase pág. 15) motivada, entre otras cosas, por la desaparición de la $s$ final de la $2 .^{2}$ pers. sing. (come $\emptyset$, comí $\emptyset$ ) y de la $1 .^{2}$ pers. pl. (comemo $\varnothing$, comiamo $\varnothing$ ). La desaparición de esa /s/ se compensa, según Hochberg (1986), en el castellano de Puerto Rico, a través de un uso más frecuente de los pronombres antepuestos tú y nosotros. Asimismo, podría contribuir a esta tendencia del uso de pronombres predeterminantes en el español la nivelación de las vocales en posición final. Para describir las diferencias tipológicas entre las dos lenguas de tipo SVO, español y francés, necesitamos, obviamente, un esquema de análisis tipológico mucho más diferenciado (véase Meyer-Hermann 1988).

LXVIII, $10^{0}-20^{\circ}-7$ 
- Por eso, no se pueden atribuir a una influencia árabe las condiciones contextuales, todavía vigentes, en el español de hoy.

- Lo que necesita una explicación es el cambio que se ha producido en el francés en las condiciones contextuales de los sujetos pospuestos.

\section{BIBLIOGRAFIA}

1. Textos analizados

Fueros de Zamora y de Salamanca

En: Fueros Leoneses de Zamora, Salamanca, Ledesma y Alba de Tormes. Edición y Estudio de Américo Castro y Federico de Onís. Madrid, 1916, págs. 1-63 (Período de orígenes hasta el año 1289, fecha del manuscrito de la presente edición).

\section{Los Fueros de Sepúlveda}

Edición crítica y apéndice documental por Emilio Sáez. Segovia, 1953, págs. 61101 (Período de orígenes hasta el año 1300; elaboración castellana y versión aumentada de un primer Fuero de Sepúlveda del año 1076 escrito en lengua latina).

\section{Vilallonga}

Grabación y transcripción de una entrevista/discusión radiofónica emitida por Antena III (Barcelona) en el mes de septiembre del año 1983 (transcripción: MH).

El País, 20/1/1986.

\section{Le Livre des Droits de Verdun}

Publicado por E.-M. Meijers y J.-J. Salverda de Grave, Haarlem, 1940, págs. 3160 (Periodo de orígenes: desde el año 1240 [primeras versiones]; la presente versión es el resultado de varias modificaciones y se terminó en el año 1340).

\section{Le masque et la plume}

Grabación y transcripción de una entrevista/discusión radiofónica emitida por Radio France el día 9 de noviembre del año 1975 (transcripción: $\mathrm{MH}$ ).

Le Monde, 25/1/1986 (última edición, núm. 12.750).

\section{Fuentes secundarias}

Antorne, G.: La coordination en francais, Paris, 1958.

Arlza, Manuel: "Contribución al estudio del orden de palabras en español". Anrario de Estudios Filológicos (Cáceres) I (1978), 1-34.

Baldingrr, Kurt: La formación de los dominios lingüísticos en la Peninsula Ibérica, Madrid, $1972^{2}$.

Bentrvoglio, Paola: Topic continuity and discontinuity in discourse: a study of spo- 
ken latin-american Spanish. En: T. Givón (ed.): Topic continuity in discourse: a quantitative cross-language study. Amsterdam/Philadelphia, 1983, págs. 255-311.

BLinkenberG, A.: L'ordre des mots en francais moderne, I. Copenhague, $1958^{2}$.

Clifford, Paula M.: Inversion of the Subject in French Narrative Prose from 1500 to the Present Day, Oxford, 1973.

CRABB, D. M.: A comparative study of word order in Old Spanish and Old French Prose Works, Washington, 1955.

Dozy, R. \& Engelmann, W.: Glossaire des mots espagnols et portugais dérivés de l'arabe, Leyden, 1869.

FANT, Lars: Estructura informativa en español. Estudio sintáctico y entonativo, Upsala, 1984.

Foulet, Lucien: Petite Syntaxe de l'Ancien Français, París, 1930.

Galmés de Fuentes, Alvaro: "Influencias sintácticas y estilísticas del árabe en la prosa medieval castellana”, Boletín de la Real Academia Española, 35 (1955), páginas 213-275, 415-451 y 36 (1956), 65-131, 255-307.

Gilissen, John: La Coutume, Brepols, 1982.

Gimeno Menéndez, Francisco: "Textos jurídicos y contexto social”, Estudios de Lingüistica (Alicante), 3 (1985/86), 341-352.

Grvón, T.: Topic continuity in discourse: an introduction. En: idem (ed.): Topic continuity in discourse: a quantitative cross-language study, Amsterdam/Philadelphia, 1983, págs. 1-41.

Hawkins, J. A.: Word Order Universals, New York (Academic Press), 1983.

Historia de España (Dir. Manuel Tuñón de Lara), tomo IV, Barcelona, 1980.

HochberG, Judith G.: “Functional compensation for /s/ deletion in Puerto Rican Spanish", Language, 62, 3 (1986), págs. 609-621.

KUEN, Heinrich: Versuch einer vergleichenden Charakteristik der romanischen Schriftsprachen, Erlangen, 1958.

LApesa, Rafael: El Fuero de Madrid. En: El Fuero de Madrid (ed. por el Ayuntamiento de Madrid), Madrid, 1963, págs. 151-163. En: ídem: Estudios de Historia Lingüística Española, Madrid, 1985, págs. 157-166.

LAPESA, Rafael: Historia de la lengua española. Novena edición corr. y aumentada, Madrid, 1981.

LE BrDors, R.: "L'inversion absolue du substantif sujet", Le Francais Moderne, IX (1941), págs. 111-128.

LEWINSKY, B.: L'ordre des mots dans "Bérinus". Göteborg, 1949.

MaUpas, Charles: Grammaire et syntaxe francoise, 3 ed. Blois, 1625.

Menendez Pidal, Gonzalo: "Cómo trabajaron las escuelas alfonsíes", Nueva Revista de Filología Hispánica, V, 4 (1951), págs. 363-380.

Menendez Pidal, Ramón: Orígenes del Español, Madrid, 1929.

Meyer-Hermann, Reinhard: Processos de topicalisą̧ão no português falado. En: J. Schmidt-Radefeldt (ed.): Homenagem a José G. Herculano de Carvalho, Coimbra, 1987 (a) (en prensa).

- La posición del sujeto en el español y portugués hablados. Ponencia para el Congreso de la Asociación Alemana de Hispanistas, Passau, 1987 (b). In: Actas... (en prensa).

: Theoretical and methodological problems in the typological analysis of Spoken Spanish. Comunicación para el XXI Congreso de la Societas Linguistica Europaea, Freiburg (RFA), 1988. 
Morales de Walters, Amparo: "La posición del sujeto en el español de Puerto Rico a la luz de la clase semántica verbal, la oposición tema-rema y el tópico oracional", Lingüistica Española Actual, IV (1982), págs. 23-38.

Muller, H. F.: "The beginnings of French fixed word-order", Modern Language Notes, LVII (1942), págs. 546-552.

Nissen, H.: L'ordre des mots dans la Chronique de Jean d'Outremeuse, Uppsala, 1943.

PEREz DE URBEL, Justo: Reconquista y repoblación de Castilla y León durante los siglos IX y X. En: La Reconquista española y la repoblación del país, Zaragoza, C.S.I.C., 1951.

Price, G.: “Aspects de l'ordre des mots dans les «Chroniques» de Froissart”. $Z R P h$, LXXVII (1961), págs. 15-48.

RICKard, P.: "The Word-Order Object-Verb-Subject", Transactions of the Philological Society (1962), págs. 1-39.

Rivero, María-Luisa: "On Left-Dislocation and Topicalization in Spanish", Linguistic Inquiry, 11, 2 (1980), págs. 363-393.

Ruhlen, M.: $A$ Guide to the Languages of the World, Stanford: Language Universals Project, Stanford University, 1975.

Sánchez Albornoz, Claudio: Despoblación y repoblación del valle del Duero, Buenos Aires, 1966.

Silva-Corvalán, Carmen: Subject expression and placement in Mexican-American Spanish. En: John Amastase \& Elias Olivares (eds.): Spanish in the United States: Socio-linguistic Aspects, New York (Cambridge University Press), 1982, págs. $93-120$

- : "Topicalización y pragmática en Español". Revista Española de Lingüística, 14 (1984), págs. 1-19.

Tomlin, Russel S.: Basic Word Order Functional Principles, London, 1986.

TORRego, Esther: “On Inversion in Spanish and some of its Effects". Lingustic Inquiry, 15, 1 (1984), págs. 103-129.

Valdé́n Baruque, Julio: León y Castilla. En: Historia de España (Dirección: Manuel Tuñón de Lara), tomo IV: Feudalismo y consolidación de los pueblos hispánicos (siglos $X I-X V$ ), Barcelona, 1980, págs. 9-197.

Wespy, L.: "Die historische Entwicklung der Inversion des Subjekts im Französischen und der Gebrauch derselben bei Lafontaine". Zeitschr. für neufranzösische Sprache und Literatur, VI (1884), págs. 150-209.

WrIGHT, Roger: "Unity and diversity among the Romance languages". Transactions of the Philological Society (1983), págs. 1-22. 